\title{
Circuit
}

Musiques contemporaines

\section{La création de Lost (1997) de Fausto Romitelli par le Nouvel Ensemble Moderne (NEM), extrait du programme}

Volume 24, numéro 3, 2014

Pactes faustiens : l'hybridation des genres musicaux après Romitelli

URI : https://id.erudit.org/iderudit/1027612ar

DOI : https://doi.org/10.7202/1027612ar

Aller au sommaire du numéro

Éditeur(s)

Les Presses de l’Université de Montréal

ISSN

1183-1693 (imprimé)

1488-9692 (numérique)

Découvrir la revue

Citer ce document

(2014). La création de Lost (1997) de Fausto Romitelli par le Nouvel Ensemble Moderne (NEM), extrait du programme. Circuit, 24(3), 79-80.

https://doi.org/10.7202/1027612ar d'utilisation que vous pouvez consulter en ligne. 


\section{La création de Lost (1997) de Fausto Romitelli par le Nouvel Ensemble Moderne (NEM), extrait du}

\section{programme}

20 septembre 1997, stage Voix nouvelles, abbaye de Royaumont (France).

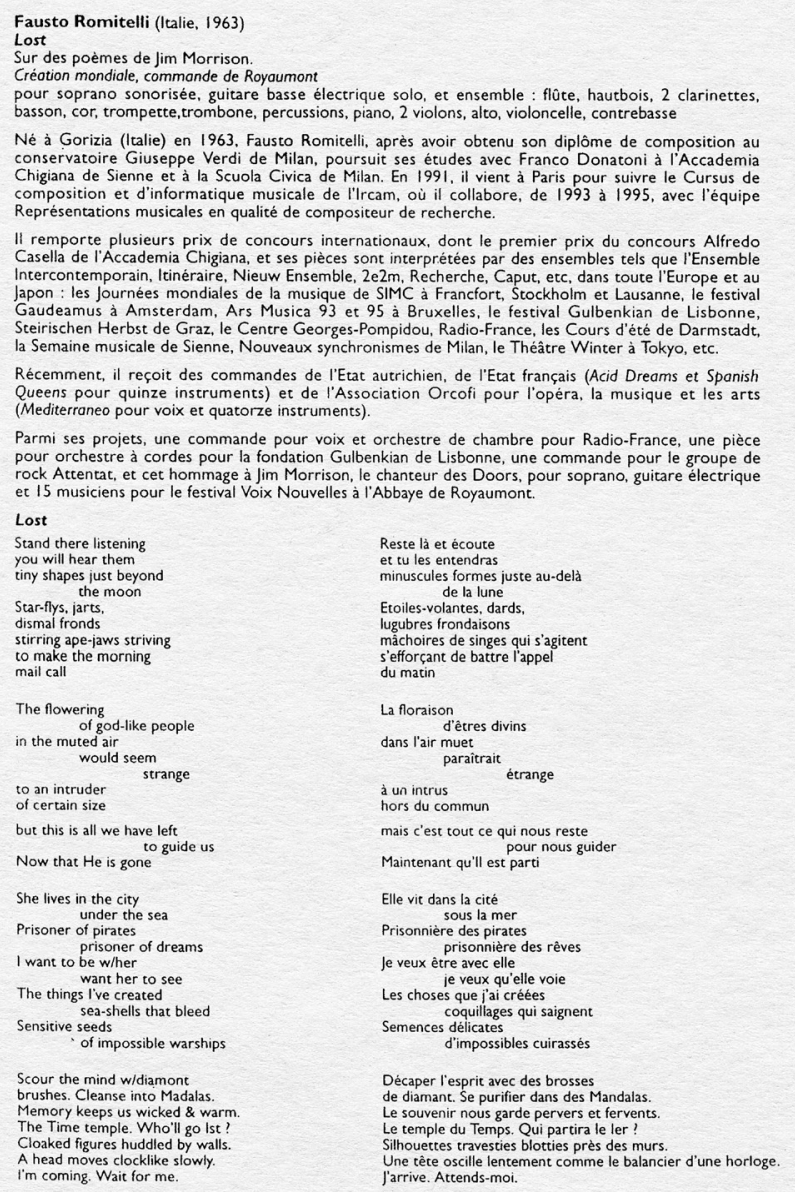


SAMEDI 20 SEPTEMBRE 1997

ANCIEN REFECTOIRE

\section{CONCERT VOIX NOUVELLES - 20H45}

Concerts en liaison avec le colloque Variétés sur l'influence du jazz, du rock et des rythmes sud-américains sur la musique contemporaine.

JeAn MARC Singier (1954):

FAusto ROMITELLI (1963):

Franco Donatoni (1927)

HeINER GOEBbels (1952)

Denys Boulanane (1955) :
A gogo, de guingois (1989) - 7

trombone, 2 percussions 2 clarinettes, basson, cor, trompette trombone, 2 percussions, alto, violoncelle, contrebasse

Lost (1997) - 20' - Création mondiale, commande de Royaumont
pour soprano sonorisée guitare basse électrique solo pour soprano sonorisée, guitare basse électrique solo, et trombone, percussions, piano, 2 violons, alto, violoncelle,
trons Contrebasse

Hot (1989) - 10'

pour saxophone solo, clarinette, trompette, trombone, entracte

La Jalousie (1991) - 18'

pour récitant et ensemble sonorisés : fîte, hautbois,

2 clarinettes, basson, cor, trompette, trombone, percussion
2 pianos, guitare, violon, alto, violoncelle, contrebasse

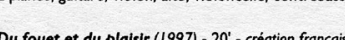

Du fouet et du plaissir (1997) - 20' - création fronçaise pour flucte, hautbois, 2 clarinettes, basson, cor, trompette,
trombone, percussion, piano, 2 violons, alto, violoncelle,
contrebasse

Marie-Annick Beliveau, soprano, Rémy Hourcade, récitant, Daniel Gauthier, saxophone, Pierre Cartier, basse électrique, Nouvel Ensemble Moderne,

Claude Hamel, violon - Alain Giguère, violon - Brian Bacon, alto - James Darling, violoncelle
René Gosselin, contrebasse - Guy Pelletier, flute - Normand Forget, haubbois - Gilles Plante, clarinette Simon Aldrich, clarinette - Michel Bettez, basson - Francis Ouellet, cor - Lise Bouchard, trompette Patrice Richer, trombone - Jacques Drouin, piano - Francis Perron, clavier - François Gauthier, percussions -

sonorisation : Régis Mitonneas

direction Lorraine Vaillancourt

Ce concert est organisé avec le soutien du Ministère de la Cuture, du Conseil Général du Val d'Oise, de la Sacem et

Cette résidence du NEM d Royaumont et so tournée en France ont été réalisées grôce à lappui du Ministère des du Québec. Voix Nouvelles remercie l'ensemble fl'tinéraire pour le prêt de matériel de sonorisation Ce concert est enregistré par France-Musique

La Fondation Royaumont est membre de la Fédération Française des Festivals Internationaux de Musique 